\title{
İmalat Sanayinde Rekabet Gücünün Ölçümü: Türkiye ve BRIC Ülkeleri Örneği
}

\author{
Measurement of the Competitiveness of the Manufacturing Industry: \\ The Case of Turkey and the BRIC Countries
}

\section{Dilek ŞAHIN ${ }^{1}$}

\begin{abstract}
ÖZET
Rekabet gücü kavramı, bir ülkenin dünya mal ve hizmet ticaretinde sahip olduğu payı göstermektedir. Rekabet gücü kavramı sadece ülkeler için değil, firmalar ve endüstriler içinde geçerlidir. Bu çalışmada Türkiye ve BRIC ülkelerinin imalat sanayi rekabet güçleri analiz edilmiştir. Açıklanmış Karşılaştırmalı Üstünlükler Endeksi ve Karşılaştırmalı İhracat Performans Endeksi kullanılmıştır. Sonuç olarak Türkiye'nin imalat sanayi rekabet gücünün SITC 6 ve SITC 8 endüstri grubunda yüksek olduğu görülmüştür. Ayrıca Türkiye'nin Brezilya, Rusya ve Hindistan karşısında imalat sanayi rekabet gücünün yüksek ancak Çin karşısında düşük olduğu görülmüştür.
\end{abstract}

Anahtar Kelimeler: Rekabet, İmalat Sanayi, Türkiye, BRIC Ülkeleri.

\section{GiRiş}

Son yıllarda küreselleşme süreciyle birlikte piyasalar daha rekabetçi bir hale bürünmüştür. Rekabetçi ortamın varlığı ise, firmaların ve ülkelerin uluslararası rekabetten kazanç sağlamak için daha fazla çaba göstermelerini gerektirmektedir. Bu durum rekabet gücünün önemini artırmıştır. Rekabet gücü bir ülkedeki bir endüstrinin/sektörün diğer ülkelerdeki endüstriye/sektöre göre daha yüksek gelir ve istihdam yaratması olarak tanımlanabilir. Rekabet gücünü endüstri, firma ve ülke (ulusal-uluslararası) bazında değerlendirmek mümkündür. Küreselleşen dünyada firma ve endüstrilerin dış ticarete açık olması ve bağlı oldukları ülkeleri temsil etmeleri nedeniyle ulusal rekabet gücü daha fazla önem kazanmıştır.

Literatürde rekabet gücünün ölçümünde Balassa (1965) tarafından ortaya atılan Açıklanmış Karşılaştırmalı Üstünlükler (AKÜ) endeksi ve türev endeksler kullanılmaktadır. Bu çalışmada ilk olarak rekabet gücü kavramından ve ölçüm yöntemlerinden

\begin{abstract}
The concept of competitiveness show that share the world with goods and services trade a country. The concept of competitiveness not only for the country, it is available in firms and industries. In this study, the competitiveness of manufacturing industry in Turkey and BRIC countries have been analyzed. Revealed Comparative Advantage Index and Comparative Export Performance Index was used. Consequently, it was found to be high SITC 6 , SITC 8 industry groups in Turkey's manufacturing competitiveness. Also, it was found Turkey, Brazil, Russia and India in the face of high competitiveness of the manufacturing industry but to be low across China.
\end{abstract}

Keywords: Competition, Manufacturing, Turkey, BRIC Countries.

bahsedilmiştir. Daha sonra çalışmada, 1996-2014 dönemleri için Türkiye ve BRIC (Brezilya, Rusya, Hindistan, Çin) ülkelerinin imalat sanayi rekabet gücü incelenmiştir. BRIC ülkelerinin seçilme nedeni, dünyanın yükselen piyasaları olarak kabul edilen bu ülkelerin dünya katma değerinden aldığı payın giderek artmasıdır. İmalat sanayi (SITC 5-8) rekabet gücünü ölçmek amacıyla Açıklanmış Karşılaştırmalı Üstünlükler Endeksi (AKÜ) ve Karşılaştırmalı İhracat Performans Endeksi (KIP) kullanılımıştır. Çalışma Türkiye ve BRIC ülkelerinin imalat sanayi rekabet gücünü karşılaştırma olanağı vererek literatüre katkıda bulunmayı amaçlamaktadır.

\section{REKABET GÜCÜ KAVRAMI VE ÖLÇÜMÜ}

Literatürde rekabet kavramı ile ilgili çok sayıda tanım bulunmaktadır. Bunun en önemli nedeni rekabet gücü tanımının ele alınan alana göre değişmesidir. Genel olarak rekabet gücü, ülkelerin serbest ve yerleşik pazar koşulları altında 
vatandaşlarının reel gelirlerini artırmaya çalışırken aynı anda ürettiği ürün ve hizmetleri uluslararası pazarlara sunabilmesi ve bunda başarılı olabilmesidir (Çivi, 2001: 22). Bir ülkenin uluslararası alanda rekabet edebilirliği; mikro açıdan firmanın, makro açıdan da endüstrinin ve ülkenin rekabet gücüne bağlı olarak değişmektedir (Altay ve Gürpınar, 2008: 258).

Firma düzeyinde rekabet gücü, herhangi bir firmanın ulusal veya uluslararası piyasalarda rakiplerine göre daha düşük maliyetli üretimde bulunma, ürünün kalitesi ve sunulan hizmet gibi kriterler bakımından rakiplerine denk veya rakiplerinde üstün olma durumudur (Koç ve Özbozkurt, 2014: 86). Firma düzeyinde rekabet gücüne mikro açıdan rekabet gücü de denilmektedir. Firmanın kar elde etme ve büyüme kapasitesini ifade eden bu rekabette firmanın rakiplerine göre daha büyük bir pazar payı elde ederek piyasanın gerektirdiği fiyat ve kalitede mal üretmesi firmanın rekabet edilebilirliğini artırmaktadır. Firmanın yenilik geliştirme kapasitesi, verimliliği, büyümesi ve karlılığı rekabet gücü açısından son derecede önemlidir (Erkekoğlu, 2008, 11). Endüstri düzeyinde rekabet gücü ise bir endüstrinin rakipleri ile aynı ya da daha ileri seviyede bir verimlilik düzeyine ulaşması, bu verimlilik düzeyini sürdürme yeteneği ya da rakipleri ile aynı ya da rakiplerinden daha düşük maliyetle üretme ve satma yeteneğidir (Markusen, 1992: 8). Ulusal (uluslararası-ülke) rekabet gücü ise, bir ülkenin serbest ve adil piyasa koşullarında uzun vadede halkının reel gelirlerini artırarak uluslararası piyasaların koşullarına ve standartlarına uygun mal ve hizmetleri üretebilme yeteneğidir (Eroğlu ve Özdamar, 2006: 87). Dünya Ekonomik Forumu'na göre ise ulusal rekabet gücü, bir ülkenin ekonomik refah ve yaşam standartlarını iyileştirebilmesi için gerekli olan ekonomik güçtür (Altıntaş ve Akpolat, 2013: 37). Ulusal düzeyde rekabet gücünü verimlilik ve üretim artışı gibi yapısal faktörler ve ülkenin uyguladığı ekonomi politikaları belirlerken; sektör bazında rekabet gücünü bu yapısal duruma ilaveten, nispi sanayi verimliliği ve nispi maliyet üstünlüğü belirlemektedir. Firma düzeyinde rekabet ise kalite, maliyet, üretim ölçeği, pazarlama gücü, firma stratejileri, yönetim-organizasyon ve beşeri sermaye gibi faktörlere bağlıdır (Saraçoğlu ve Köse, 2000: 1).

Şekil 1'de firma, endüstri ve uluslararası düzeyde rekabet gücü kavramı açıklanırken önem verilen konular gösterilmiştir. Bu bağlamda firma, endüstri ve uluslararası düzeyde rekabet gücünü gösteren bir piramit yer almaktadır. Şekil 1'de firma düzeyinde tanımlamadan uluslararası düzeyde tanımlamaya geçildikçe önem verilen konu sayısının arttığı ve tabana doğru inildikçe rekabet gücü kavramının daha kapsamlı bir hal aldığı görülmektedir. Maliyet, fiyat avantajı ve verimlilik, fiyat dışı rekabet avantajı firma düzeyindeki rekabet gücünü yansıtırken; bunlara dış ticaret performansı eklendiğinde endüstriyel rekabet gücüne; kişi başına reel mili gelir performansı ve yaşam kalitesi performansı dâhil edildiğinde ise uluslararası rekabet gücü kavramına ulaşılmaktadır. Firma ve endüstri düzeyinden uluslararası düzeye geçildiğinde makroekonomik konuların daha fazla önem kazandığı dikkat çekmektedir. Bu bağlamda dar anlamda rekabet gücü firma düzeyinde (mikro), geniş anlamda rekabet gücü ise, uluslararası düzeyde (makro) rekabet gücüne karşılık gelmektedir.

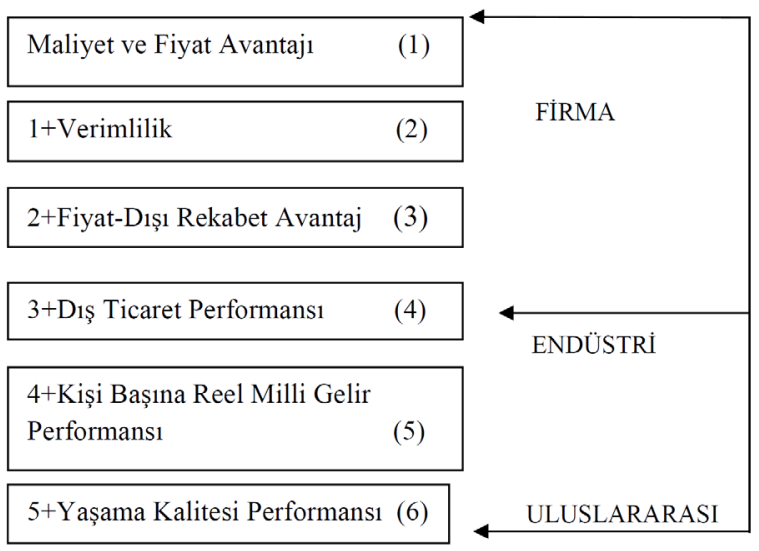

Kaynak: Aktan ve Vural, 2004: 12

Şekil 1: Rekabet Gücü Kavramları Piramidi

Geleneksel rekabet gücünün firma, endüstri ve uluslararası düzeyde yapılan incelemeleri farklı tanımları gerektirmiştir. Firma, endüstri ve uluslararası rekabet düzeyi; karlılık, verimlilik, maliyet, pazar payı, kişi başına verimlilik, dış ticaret performansı, üretim faktörü stoku, toplam faktör verimliliği, dış ticaret haddi, ürünün teknolojik yoğunluğu ve rekabetin sürdürülebilirliği açısından karşılaştırılmaktadır. Karlılık, verimlilik ve düşük maliyetin firma açısından rekabet gücü kazanımında en önemli üç faktördür. Endüstri açısından, pazar payını artırma ve koruma, kişi başına verimlilik, dış ticaret performansı, toplam faktör verimliliği, rekabet gücünü kazanmanın yanı sıra sürdürülebilirliği de önemli faktörlerdir. Ulusal düzeyde rekabet gücü açısından firma ve endüstri açısından önemli olan faktörlerle birlikte üretim faktörü stoku ve teknoloji geliştirip 
üründe kullanmanın ayrı bir öneme sahip olduğu görülmektedir (Dulupçu, 2001: 91).

Rekabet gücünü belirleyen etkenler firma içi etkenler ve firma dışı etkenler olarak iki kategoride toplanmaktadır. Firma içi etkenler arasında, firmanın ürettiği malın kalitesi, maliyeti ve fiyatı önem taşımaktadır. Maliyetler arasında ise işgücü maliyeti, sermaye maliyeti, ithalat maliyeti, vergi maliyeti, sosyal güvenlik maliyeti ön plana çıkmaktadır. Bunun dışında verimlilik, kaynakların etkin kullanımı, firmalarda kullanılan bilgi teknolojisi, yenilikçilik ve yaratıcılık gibi faktörler rekabet gücünü belirleyen firma içi diğer etkenler arasında yer almaktadır. Rekabet gücünü belirleyen firma dışı başlıca etkenler olarak firmanın faaliyette bulunduğu sektörlerdeki rekabet yoğunluğu, döviz kurları, yabancı sermaye, doğal kaynaklar, mali piyasaların yapısı, uluslararası ticaret ve hukuk sistemi yer almaktadır (Aktan ve Vural, 2004: 27-29).

Ülkeler arasında rekabet gücünü ölçmek amacıyla çok sayıda gösterge kullanılmaktadır. Rekabet gücünü ölçmedeki amaç, ülke ile dış ticaret yaptığı ülkeler arasındaki ilişkileri ortaya koymak ve ülkenin makro ekonomik performansını ölçmeye yardım etmektir (Saraçoğlu ve Köse, 2000: 1). Rekabet gücünün ölçülmesinde en yaygın araç reel kur hesaplamalarıdır. Bunun yanı sıra, ücretlerdeki gelişmeler, işgücü verimliliği, işsizlik, eğitilmiş işgücü ve $\mathrm{Ar}$-Ge faaliyetleri gibi yapısal göstergelerin yanı sıra, ürün kalitesi, satış sonrası hizmetler gibi bazı niteliksel faktörlerde rekabet gücünün ölçülmesinde dikkate alınmaktadır (Kösekahyaoğlu ve Özdamar, 2011: 32).

Ancak dış ticaretin rekabet gücünün ölçülmesinde ticaret performans endeksleri kullanılmaktadır. Bu endeksler arasında yer alan ve literatürde sıklıkla kullanılan endeks Balassa (1965) tarafından geliştirilen Açıklanmış Karşılaştırmalı Üstünlükler (AKÜ) endeksi ve bunun türevleridir. Balassa (1965) tarafından geliştirilen AKÜ endeksinin "Göreli İhracat-lithalat Oranları Ölçütü" şeklinde yazılması mümkündür. Söz konusu bu endeks şu şekilde yazılmaktadır:

$$
A K \ddot{U}_{\mathrm{ij}}=\left(\mathrm{X}_{\mathrm{ij}}\right) /\left(\mathrm{X}_{\mathrm{it}}\right) /\left(\mathrm{M}_{\mathrm{ij}}\right) /\left(\mathrm{M}_{\mathrm{it}}\right)
$$

(1) numaralı eşitlikte de yer alan $\mathrm{AKÜ}_{\mathrm{ij}}{ }^{\prime} \mathrm{i}$ ülkesinin j mal grubundaki açıklanmış karşılaştırmalı üstünlük katsayısını; $\left(X_{i j}\right)$ i ülkesinin j mal grubundaki ihracatını; $\left(X_{i t}\right)$ i ülkesinin toplam ihracatını; $\left(M_{i j}\right)$ i ülkesinin j mal grubundaki ithalatını, $\left(M_{i t}\right)$ ise i ülkesinin toplam ithalatını göstermektedir. Bir ülkenin farklı mal grupları için hesaplanan AKÜ endeksi 1'den ne kadar büyükse (küçükse), ülkenin o mal grubundaki ticaret performansı o kadar büyüktür (küçüktür). AKÜ endeksinin 1'den büyük olması (küçük) o sektörde rekabet gücünün yüksek (düşük) olduğunu göstermektedir.

Ülkeler arasında dış ticaret rekabet gücünün karşılaştırılmasında "Karşılaştırmalı İhracat Performans Endeksi (KiP)" de kullanılmaktadır. Bu endeks şu şekilde ifade edilmektedir:

$$
\mathrm{KIP}_{\mathrm{irj}}=\left(\mathrm{X}_{\mathrm{ij}} / \mathrm{X}_{\mathrm{rij}}\right) /\left(\Sigma \mathrm{X}_{\mathrm{it}} / \Sigma \mathrm{X}_{\mathrm{rt}}\right)
$$

(2) numaralı eşitlikte geçen $\mathrm{KIP}_{\mathrm{irj}}$ i ülkesinin rakip ülke karşısında j mal grubundaki karşılaştırmalı ihracat performans katsayısını, $\left(X_{i j}\right)$ i ülkesinin $j$ mal grubundaki ihracatını, $\left(X_{r j}\right)$ rakip ülkelerin $j$ mal grubundaki ihracatını, $\left(\Sigma X_{i t}\right)$ i ülkesinin toplam ihracatını, $\Sigma\left(X_{r t}\right)$ ise rakip ülkelerin toplam ihracatını göstermektedir. Endeks değeri 1'den büyük ise bu durum ülkenin o mal grubundaki ihracatta avantajlı olduğunu ifade etmektedir. AKÜ belirli bir ülkenin mal grubundaki rekabet gücü ölçmede kullanılırken; KIP endeksi iki farklı ülkenin belirli mal grubundaki rekabet güçlerini karşılaştırma imkânı sağlamaktadır.

\section{LITERATÜR TARAMASI}

Literatürde AKÜ kapsamında yapılan bazı çalışmaları aşağıdaki gibi özetlemek mümkündür:

Yılmaz (2003), Türkiye'nin AB'deki rekabet gücü, $A B-15$ ve 5 aday ülke (Bulgaristan, Çek Cumhuriyeti, Macaristan, Romanya, Polonya) ile kıyaslanarak ölçülmüştür. Çalışmada SITC teknoloji sınıflandırmasına göre rekabet gücü ölçümü 19961999 dönemlerine ilişkin yapılmıştır. Türkiye dâhil bu beş ülkenin emek yoğun malların ihracatında karşılaştırmalı üstünlüğe sahip olduğu görülmüştür. Türkiye, Çek Cumhuriyeti, Romanya ve kısmen Bulgaristan emek yoğun malların ihracatında yüksek bir rekabet gücüne sahiptir. Çek Cumhuriyeti'nin hammadde yoğun malların ihracatında karşılaştırmalı üstünlüğe sahip olduğu görülmüştür. Sermaye yoğun malların ihracatında; Çek Cumhuriyeti, Bulgaristan ve kısmen Romanya nispi rekabet gücüne sahiptir. 5 ülke ve Türkiye, kolay taklit edilen araştırma bazlı mallar ve zor taklit edilen araştırma bazlı malların inracatında karşılaştırmalı dezavantaja sahiptir. Fakat Macaristan nispi olarak diğer ülkelerden daha iyi durumdadır. Çek Cumhuriyeti ve Macaristan diğer 
dört ülke ile kıyaslandığında ihracat yapılarını emek yoğun mallardan sermaye yoğun ve kolay taklit edilen ve zor taklit edilen araştırma bazlı mallara doğru kaydırmaktadır. Türkiye hammadde yoğun ve emek yoğun malların ihracatında karşılaştırmalı üstünlüklere sahip olup, kolay taklit edilen ve zor taklit edilen araştırma bazlı malların ihracatında karşılaştırmalı dezavantaja sahiptir. AB-15 de, sermaye yoğun ve zor taklit edilen araştırma bazı ı malların ihracatında karşılaştırmalı üstünlüğe sahiptir.

Amighini (2005), bilgi ve iletişim teknolojileri sanayilerinde Çin'in dünya piyasasındaki yeri araştırımıştır. Çalışmada Balassa'nın Açıklanmış Karşılaştırmalı Üstünlükler Endeksi ve net ticaret endeksi kullanılarak 1991 ve 2001 yılı için analiz yapılmıştır. Çalışmada SITC 5 haneli ürün sınıflandırması kullanıımıştır. Sonuç olarak, Çin 19912001 yılları arasında niteliksiz emek yoğun sektörlerde uzmanlaşmıştır. Teknoloji yoğun sektörlerde Çin halen karşılaştırmalı dezavantaja sahip olmakla birlikte, seçilen bazı alt sektörde rekabet gücü yükselmektedir. 1990'lardan itibaren teknoloji yoğun sektörlerde rekabet gücü artmakta özellikle de son on yılda elektronik makine, bilişim, telekom ve ofis ekipmanları ve elektrikli eşyalarda rekabet gücü yükselmektedir. Bilgi ve iletişim teknolojilerindeki gelişmelerde ülkeye giren yabancı sermaye yatııımları ve ülkenin küresel üretim ağlarındaki rolü etkin olmuştur.

Vergil ve Yıldırım (2006), Türkiye'nin $A B$ piyasalarındaki rekabet gücünü ölçmek amacıyla 1993-2002 yılları için 215 ihracat sektörünün açıklanmış karşılaş̧ırmalı üstünlük endeksleri hesaplanmıştır. Türkiye'nin $A B$ piyasalarındaki rekabet gücü ile gümrük birliği arasındaki ilişkinin tahmin edildiği sabit etkiler panel veri analizinde, gümrük birliğinin hem Türkiye'nin ileri teknoloji mallarında hem de taklidi zor araştırma yoğun mallarındaki rekabet gücünü olumlu yönde etkilediği sonucuna ulaşılırken, sermaye yoğun mallardaki ve ara teknoloji mallarındaki rekabet gücünü olumsuz yönde etkilediği sonucuna varılmıştır. Başka bir ifadeyle Türkiye'nin ileri teknoloji mallarındaki ve taklidi zor araştırma yoğun mallarındaki rekabet gücü ile gümrük birliği arasındaki ilişki yakalama paradigmasını desteklerken, sermaye yoğun mallardaki ve ara teknoloji mallarındaki rekabet gücü ile gümrük birliği arasındaki ilişki kutuplaşma teorisini destekleyen sonuçlar üretmiştir.
Eroğlu ve Özdamar (2006), çalışmada beyaz eşya sektörünün karşılaştırmalı üstünlüğünde görülen olumlu durumun daha çok sektörün kendi içsel dinamiklerinden kaynaklandığı, Gümrük Birliği'nin getirdiği yüksek düzeydeki rekabetçi yapıya sektörün uyum sağlamış olduğu ve karşılaştırmalı üstünlüğün giderek arttığı görülmüştür.

Erkan (2011), 1993-2009 yılları arasında Türkiye'nin tekstil ve hazır giyim sektöründe rekabet gücünü açıklanmış karşılaştırmalı üstünlükler yaklaşımı ile ölçmüştür. SITC Rev.3, dört haneli bazda tekstil sektörüne ait 59, hazır giyim sektörüne ait 37 ürün grubuna ilişkin açıklanmış karşılaştırmalı üstünlük katsayıları hesaplanmıştır. AKÜ katsayılarının hesaplanmasında Vollrath Endeksi ve İhracat-Ithalat Oranı endeksi kullanıımıştır. Çalışmanın sonucunda Türkiye'de tekstil sektörünün alt ürün grubu ihracatından 43'ünde, hazır giyim sektörünün alt ürün grubu ihracatında, 34'ünde rekabet avantajı bulunduğu tespit edilmiştir.

Kösekahyaoğlu ve Özdamar (2011), Türkiye, Çin ve Hindistan'ın rekabet güçleri, 1990-2009 dönemi dikkate alınarak hammadde yoğun mallar, emek yoğun mallar, sermaye yoğun mallar, kolay taklit edilen ve zor taklit edilen araştırma bazlı mallar olarak beş farklı mal grubu için ayrı olarak incelenmiştir. Ülkelerin rekabet güçlerinin ölçütü olarak Açıklanmış Karşılaştırmalı Üstünlük, İhracat Uzmanlık İndeksi ve Karşılaştırmalı İhracat Performans İndeksi kullanılmıştır. Çalışmadan elde edilen bulgular incelenen üç ülkenin rekabet gücünün beklenildiği üzere temelde emek yoğun mallara dayandığı görülmüştür.

Altıntaş ve Akpolat (2013), Türkiye'nin AB-27 ülkeleri ile olan dış ticaretinde tekstil sektörünün rekabet gücü ölçülmüştür. 2004-2011 dönemi verileri kullanılarak Balassa, Vollrath ve KiP endeksleri ile rekabet düzeyi incelenmiş ve 2004-2011 döneminde Türkiye'nin AB-27 ülkelerine karsı karşılaştırmalı rekabet avantajına sahip olduğu ve 2011 yılına gelindiğinde söz konusu rekabet avantajının en yüksek düzeye ulaştığı sonucuna ulaşılmıştır.

Şahin (2015), Türkiye'nin tekstil ve hazır giyim sektörünün rekabet gücü Çin ile karşılaştırılmıştır. Çalışma 1995-2013 yıllarını kapsamaktadır. Rekabet gücü göstergesi olarak, Balassa tarafından geliştirilmiş olan açıklanmış karşılaştırmalı üstünlükler yaklaşımı esas alınmıştır ve SITC Rev.3 iki ve üç haneli ürün grupları açısından hesaplama yapılmıştır. Sonuç 
olarak Türkiye ve Çin'in tekstil ve hazır giyim sanayinde rekabet gücünün yüksek olduğu görülmüştür. Ancak Türkiye'nin Açıklanmış Karşılaştırmalı Üstünlük katsayısının Çin'e göre daha yüksek olduğu sonucuna ulaşılmıştır.

\section{VERI SETI VE YÖNTEM}

Türkiye ve BRIC ülkelerinin imalat sanayi dış ticaretinin rekabet gücünün incelendiği bu çalışmada uluslararası ticaret sınıflamasına göre (SITC Rev.3) SITC 5-8 olarak adlandırılan imalat sanayi ürünleri analiz edilmiştir.

Bu ürün grupları şu şekildedir:

SITC 5: Başka Yerde Belirtilmeyen Kimya Sanayi Ürünleri, SITC 6:Başlıca Sınıflara Ayrılarak İşlenmiş Mallar, SITC 7: Makine ve Ulaştırma Araçları, SITC 8: Çeşitli Mamul Eşya.

Çalışmada rekabet gücünün tespiti AKÜ (Açıklanmış Karşılaştırmalı Üstünlükler Endeksi) ve KiP (Karşılaştırmalı İhracat Performans Endeksi) yardımıyla hesaplanmıştır. Çalışmada AKÜ endeksi kullanılırken Türkiye ve BRIC ülkelerinin toplam dünya ticaretinin rekabet gücü hesaplanmıştır. Çalışmada 1996 yılı başlangıç yılı olarak alınmış ve 2000-2014 dönemi analiz edilmiştir. Analiz yılı olarak 1996 yılının seçilme nedeni Türkiye'nin bu tarihte $A B$ ile Gümrük Birliği anlaşmasını imzalamış olmasıdır. Çalışmada kullanılan ithalat ve ihracat verileri Birleşmiş Milletlerin (UN) Comtrade veri tabanından alınmıştır.

\section{BULGULAR VE DEĞERLENDIRMELER}

Burada uygulamalar ilk olarak AKÜ endeksine göre daha sonra KiP endeksine göre yapılarak yorumlanmıştır.

\subsection{Rekabet Gücünün Belirlenmesinde AKÜ Endeksinin Hesaplanması}

Tablo 1'de Türkiye'nin imalat sanayinde (SITC 5-8) rekabet gücü endeks değerleri yer almaktadır. Tablo 1'den yola çıkılarak Türkiye'de SITC 6 (Başlıca Sınıflara Ayrılarak İşlenmiş Mallar), SITC 8 (Çeşitli Mamul Eşya) sektöründe rekabet gücünün yüksek olduğu görülmektedir. SITC 7 (Makine ve Ulaştırma Araçları) endüstrisinde bazı dönemler endeks değerinin 1'den büyük olduğu (rekabet avantajına sahip olduğu) görülürken bazı dönemlerde 1'den küçük olduğu (rekabet dezavantajına) görülmektedir. SITC 5 (Başka Yerde Belirtilmeyen Kimya Sanayi Ürünleri) endüstri grubunda ise Türkiye'nin rekabet gücüne sahip olmadığı görülmektedir.

Tablo 1: Türkiye'nin İmalat Sanayi Rekabet Gücü: AKÜ Endeksi (1996-2014)

\begin{tabular}{|c|c|c|c|c|}
\hline Sektörler & $\begin{array}{c}\text { (Başka Yerde Belirtilmeyen } \\
\text { Kimya Sanayi Ürünleri) }\end{array}$ & $\begin{array}{c}\text { (Başlıca Sınıflara Ayrılarak } \\
\text { işlenmiş Mallar) }\end{array}$ & $\begin{array}{c}\mathbf{7} \\
\text { (Makine ve } \\
\text { Ulaştırma Araçları) }\end{array}$ & $\begin{array}{c}\mathbf{8} \\
\text { (Çeşitli } \\
\text { Mamul Eşya) }\end{array}$ \\
\hline 1996 & 0,27 & 1,42 & 0,29 & 4,48 \\
\hline 2000 & 0,26 & 1,81 & 0,51 & 4,60 \\
\hline 2005 & 0,34 & 2,01 & 1,12 & 4,77 \\
\hline 2006 & 0,31 & 1,52 & 0,97 & 3,38 \\
\hline 2007 & 0,32 & 1,52 & 1,12 & 3,39 \\
\hline 2008 & 0,35 & 1,77 & 1,20 & 2,91 \\
\hline 2009 & 0,36 & 1,88 & 1,07 & 2,91 \\
\hline 2010 & 0,33 & 1,44 & 0,81 & 2,35 \\
\hline 2011 & 0,37 & 1,70 & 0,90 & 2,57 \\
\hline 2012 & 0,48 & 2,04 & 1,08 & 3,29 \\
\hline 2013 & 0,42 & 1,67 & 0,92 & 2,79 \\
\hline 2014 & 0,46 & 1,82 & 1,07 & 3,19 \\
\hline
\end{tabular}

Kaynak : UN Comtrade veri tabanından yola çıkılarak tarafımızca hesaplanıp düzenlenmiştir.

Tablo 2, tablo 3, tablo4 ve tablo $5^{\prime}$ de BRIC ülkelerinin imalat sanayinde (SITC 5-8) rekabet gücü endeks değerleri yer almaktadır. Bu tablolardan yola çıkılarak BRIC ülkeleri için şunlar söylenebilir:
Brezilya; Brezilya'nın imalat sanayi ürün gruplarından SITC 6 endüstrisinde 1996-2009 yılları arasında endeks değerinin 1'den büyük olduğu dolayısıyla rekabet gücünün yüksek olduğu 
görülmektedir. Ancak, 2010 yılından itibaren endeks değeri 1'in altına düşerek rekabet gücü kaybedilmiştir. SITC 5, SITC 7 ve SITC 8 endüstri gruplarında ise endeks değerinin ele alınan dönemlerde 1'den küçük olduğu dolayısıyla rekabet dezavantajının olduğu görülmektedir.

Tablo 2: Brezilya'nın İmalat Sanayi Rekabet Gücü: AKÜ Endeksi (1996-2014)

\begin{tabular}{|c|c|c|c|c|}
\hline Sektörler & $\begin{array}{c}\text { (Başka Yerde Belirtilmeyen } \\
\text { Kimya Sanayi Ürünleri) }\end{array}$ & $\begin{array}{c}\mathbf{6} \\
\text { (Başlıca Sınıflara Ayrılarak } \\
\text { Işslenmiş Mallar) }\end{array}$ & $\begin{array}{c}\mathbf{7} \\
\text { (Makine ve } \\
\text { Ulaştırma Araçları) }\end{array}$ & $\begin{array}{c}\mathbf{8} \\
\text { (Çeşitli } \\
\text { Mamul Eşya) }\end{array}$ \\
\hline 1996 & 0,41 & 2,29 & 0,52 & 0,85 \\
\hline 2000 & 0,36 & 2,01 & 0,66 & 1,06 \\
\hline 2005 & 0,30 & 1,77 & 0,68 & 0,67 \\
\hline 2006 & 0,37 & 1,58 & 0,64 & 0,58 \\
\hline 2007 & 0,34 & 1,46 & 0,74 & 0,56 \\
\hline 2008 & 0,32 & 1,38 & 0,58 & 0,47 \\
\hline 2009 & 0,34 & 1,16 & 0,43 & 0,41 \\
\hline 2010 & 0,34 & 0,93 & 0,42 & 0,37 \\
\hline 2011 & 0,31 & 0,98 & 0,39 & 0,31 \\
\hline 2012 & 0,32 & 0,97 & 0,41 & 0,29 \\
\hline 2013 & 0,31 & 0,98 & 0,48 & 0,28 \\
\hline 2014 & 0,29 & 1,10 & 0,40 & 0,29 \\
\hline
\end{tabular}

Kaynak : UN Comtrade veri tabanından yola çıkılarak tarafımızca hesaplanıp düzenlenmiştir.

Rusya; Rusya'nın SITC 6 endüstri grubunda 19962009 döneminde endeks değeri 1'den büyük ve rekabet avantajı söz konusudur. Ancak 2010 yılından itibaren rekabet gücünün azaldığı görülmektedir.
SITC 5, SITC 7 ve SITC 8 endüstri gruplarında ise endeks değeri 1'den küçük olup bu endüstrilerde rekabet dezavantajı görülmektedir.

Tablo 3: Rusya'nın İmalat Sanayi Rekabet Gücü: AKÜ Endeksi (1996-2014)

\begin{tabular}{|c|c|c|c|c|}
\hline Sektörler & $\begin{array}{c}\mathbf{5} \\
\text { (Başka Yerde Belirtilmeyen } \\
\text { Kimya Sanayi Ürünleri) }\end{array}$ & $\begin{array}{c}\mathbf{6} \\
\text { (Başlıca Sınıflara Ayrılarak } \\
\text { işlenmiş Mallar) }\end{array}$ & $\begin{array}{c}\mathbf{7} \\
\text { (Makine ve } \\
\text { Ulaştırma Araçları) }\end{array}$ & $\begin{array}{c}\mathbf{8} \\
\text { (Çeşitli } \\
\text { Mamul Eşya) }\end{array}$ \\
\hline 1996 & 0,81 & 1,87 & 0,35 & 0,21 \\
\hline 2000 & 0,50 & 1,28 & 0,25 & 0,27 \\
\hline 2005 & 0,33 & 1,14 & 0,10 & 0,10 \\
\hline 2006 & 0,31 & 1,21 & 0,08 & 0,08 \\
\hline 2007 & 0,39 & 1,21 & 0,08 & 0,08 \\
\hline 2008 & 0,47 & 1,03 & 0,07 & 0,06 \\
\hline 2009 & 0,31 & 1,06 & 0,09 & 0,07 \\
\hline 2010 & 0,31 & 0,94 & 0,07 & 0,04 \\
\hline 2011 & 0,36 & 0,84 & 0,05 & 0,03 \\
\hline 2012 & 0,38 & 0,84 & 0,07 & 0,18 \\
\hline 2013 & 0,18 & 0,59 & 0,09 & 0,17 \\
\hline 2014 & na & na & na & na \\
\hline
\end{tabular}

Kaynak : UN Comtrade veri tabanından yola çıkılarak tarafımızca hesaplanıp düzenlenmiştir. na: ilgili yıla ilişkin veriye ulaşılamadığını göstermektedir. 
Çin; Çin'de ele alınan dönemler itibariyle SITC 6, SITC 7 ve SITC 8 endüstri grubunda endeks değerinin 1 'den büyük dolayısıyla bu endüstrilerde rekabet gücünün yüksek olduğu görülmektedir. SITC 5 endüstri grubunda ise rekabet avantajı söz konusu değildir.

Tablo 4: Çin'in İmalat Sanayi Rekabet Gücü: AKÜ Endeksi (1996-2014)

\begin{tabular}{|c|c|c|c|c|}
\hline Sektörler & $\begin{array}{c}\text { (Başka Yerde Belirtilmeyen } \\
\text { Kimya Sanayi Ürünleri) }\end{array}$ & $\begin{array}{c}\text { (Başlıca Sınıflara } \\
\text { Ayrılarak Isslenmiş Mallar) }\end{array}$ & $\begin{array}{c}\mathbf{7} \\
\text { (Makine ve } \\
\text { Ulaştırma Araçları) }\end{array}$ & $\begin{array}{c}\mathbf{8} \\
\text { (Çeşitli } \\
\text { Mamul Eşya) }\end{array}$ \\
\hline 1996 & 0,46 & 0,86 & 0,61 & 6,36 \\
\hline 2000 & 0,36 & 0,93 & 0,82 & 6,23 \\
\hline 2005 & 0,41 & 1,43 & 1,09 & 2,88 \\
\hline 2006 & 0,44 & 1,74 & 1,10 & 2,89 \\
\hline 2007 & 0,45 & 1,74 & 1,14 & 2,77 \\
\hline 2008 & 0,52 & 1,91 & 1,19 & 2,69 \\
\hline 2009 & 0,43 & 1,35 & 1,14 & 2,78 \\
\hline 2010 & 0,49 & 1,58 & 1,18 & 2,78 \\
\hline 2011 & 0,56 & 1,88 & 1,26 & 3,18 \\
\hline 2012 & 0,58 & 2,09 & 1,35 & 3,61 \\
\hline 2013 & 0,55 & 2,16 & 1,29 & 3,72 \\
\hline 2014 & 0,61 & 2,04 & 1,30 & 3,96 \\
\hline
\end{tabular}

Kaynak : UN Comtrade veri tabanından yola çıkılarak tarafımızca hesaplanıp düzenlenmiştir.

Hindistan; Hindistan'da ise SITC 5, SITC 6 ve SITC 8 endüstri gruplarında endeks değerinin 1'den büyük olduğu ve bu endüstrilerde Hindistan'ın rekabet gücüne sahip olduğu görülmektedir. SITC 7 endüstri grubunda ise endeks değerinin 1'in altında olduğu ancak yıllar itibariyle bu endüstride endeks değerinin dolayısıyla rekabet gücünün arttığı görülmektedir.

Tablo 5: Hindistan'ın İmalat Sanayi Rekabet Gücü: AKÜ Endeksi (1996-2014)

\begin{tabular}{|c|c|c|c|c|}
\hline Sektörler & $\begin{array}{c}\text { (Başka Yerde Belirtilmeyen } \\
\text { Kimya Sanayi Ürünleri) }\end{array}$ & $\begin{array}{c}\mathbf{6} \\
\text { (Başlıca Sınıflara Ayrılarak } \\
\text { Işlenmiş Mallar) }\end{array}$ & $\begin{array}{c}\mathbf{7} \\
\text { (Makine ve } \\
\text { Ulaştırma Araçları) }\end{array}$ & $\begin{array}{c}\mathbf{8} \\
\text { (Çeşitli } \\
\text { Mamul Eşya) }\end{array}$ \\
\hline 1996 & 0,70 & 1,99 & 0,43 & 7,07 \\
\hline 2000 & 1,15 & 2,31 & 0,49 & 5,67 \\
\hline 2005 & 1,18 & 2,08 & 0,52 & 4,53 \\
\hline 2006 & 1,28 & 2,46 & 0,47 & 4,43 \\
\hline 2007 & 1,18 & 2,21 & 0,51 & 3,86 \\
\hline 2008 & 1,03 & 2,26 & 0,66 & 4,79 \\
\hline 2009 & 1,02 & 1,74 & 0,70 & 4,90 \\
\hline 2010 & 1,08 & 1,82 & 0,79 & 4,16 \\
\hline 2011 & 1,13 & 1,67 & 0,83 & 4,56 \\
\hline 2012 & 1,34 & 2,10 & 0,84 & 4,03 \\
\hline 2013 & 1,38 & 2,01 & 0,84 & 3,93 \\
\hline 2014 & 1,44 & 1,86 & 0,93 & 4,14 \\
\hline
\end{tabular}

Kaynak : UN Comtrade veri tabanından yola çıkılarak tarafımızca hesaplanıp düzenlenmiştir. 


\subsection{Rekabet Gücünün Belirlenmesinde KiP Endeksinin Hesaplanması}

Türkiye'nin Brezilya karşısındaki karşılaştırmalı ihracat performans endeksi şekil 2'de verilmiştir. Bu grafikte Türkiye'nin Brezilya karşısında SITC 6, SITC 7 ve SITC 8 endüstri grubunda katsayı değerlerinin yüksek olduğu görülmektedir. SITC 5 grubunda ise endeks değeri bazı dönemler 1'in üstüne çıkmasına rağmen genel olarak ihracat performansının 1'den küçük olduğu görülmektedir.

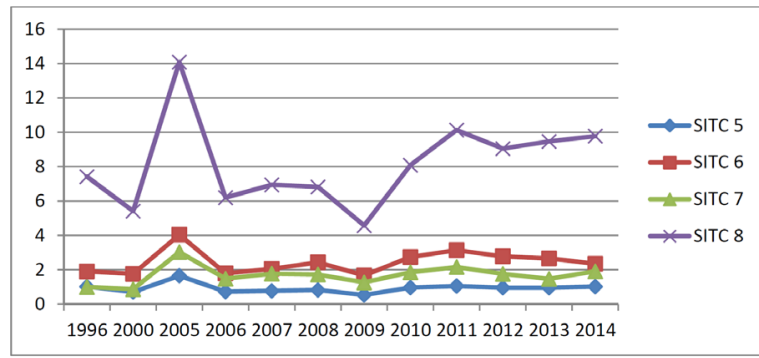

Kaynak: UN Comtrade veri tabanından yola çıkılarak tarafımızca hesaplanıp düzenlenmiştir.

Şekil 2: KIP Endeksi: Türkiye-Brezilya (1996-2014)

Türkiye'nin Rusya karşısındaki karşılaştırmalı ihracat performans endeksi şekil 3'de verilmiştir. Şekil 3'den hareketle Türkiye'nin özellikle SITC 8 endüstri grubunda daha yüksek bir ihracat performansına sahip olduğu görülmektedir. Ayrıca SITC 5, SITC 6 ve SITC 7 endüstri gruplarında da Türkiye'nin Rusya'ya göre rekabet üstünlüğü olduğu görülmektedir.

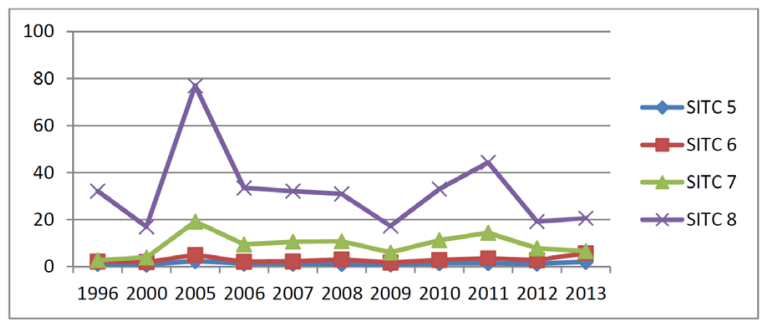

Kaynak: UN Comtrade veri tabanından yola çıkılarak tarafımızca hesaplanıp düzenlenmiştir.

Not: Rusya'ya ait 2014 verilerine ulaşılamadığından dolayı hesaplama 2013 yılına kadar yapılabilmiştir.

Şekil 3: KIP Endeksi:Türkiye-Rusya (1996-2013)

Şekil 4'de Türkiye'nin Hindistan karşısındaki KiP endeks değerleri yer almaktadır. Türkiye'nin SITC 6, SITC 7 ve SITC 8 endüstri grubunda Hindistan'a göre yüksek bir ihracat performansına sahip olduğu görülmektedir. Buna karşın SITC 5 endüstri grubunda
Hindistan'ın Türkiye'ye göre ihracat performansının daha yüksek olduğu görülmektedir.

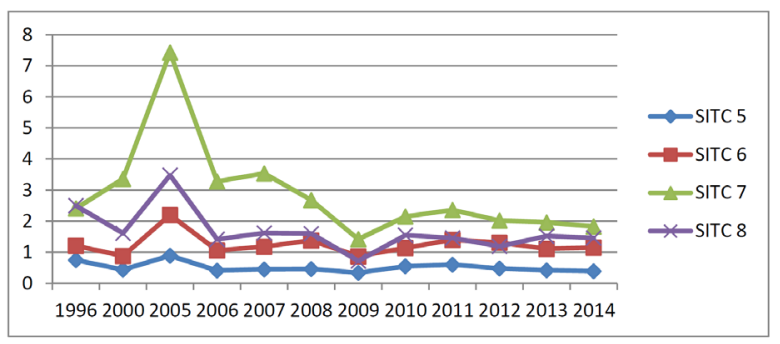

Kaynak: UN Comtrade veri tabanından yola çıkılarak tarafımızca hesaplanıp düzenlenmiştir.

Şekil 4: KiP Endeksi: Türkiye-Hindistan (1996-2014)

Türkiye'nin Çin karşısındaki karşılaştırmalı ihracat performans endeksi şekil 5'de verilmiştir. Bu şekilde SITC 6 endüstri grubunda katsayının 1'den büyük olduğu görülmektedir. SITC 5 endüstri grubunda ise KiP endeks değerinin artış trendi sergilediği görülmektedir. Buna karşılık SITC 7 ve SITC 8 endüstri grubunda Çin'in Türkiye karşısındaki ihracat performansının daha yüksek olduğu anlaşılmaktadır.

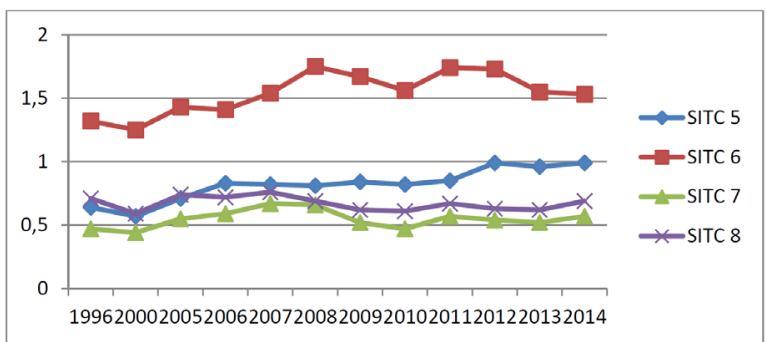

Kaynak: UN Comtrade veri tabanından yola çıkılarak tarafımızca hesaplanıp düzenlenmiştir.

Şekil 5: KIP Endeksi: Türkiye-Çin (1996-2014)

\section{SONUÇ}

Rekabet gücü kavramı, bir ülkenin dünya mal ve hizmet ticaretinde sahip olduğu payı göstermektedir. Rekabet gücü firma, endüstri ve ulusal düzeyde olmak üzere üç kategoride ele alınmaktadır. Türkiye ile BRIC ülkelerinin imalat sanayi rekabet gücünün ölçüldüğü bu çalışmada rekabet gücünün ölçümünde literatürde sıklıkla kullanılan Açıklanmış Karşılaştırmalı Üstünlükler Endeksi ve Karşılaştırmalı İhracat Performans Endeksi kullanılmıştır.

Çalışma sonuçlarına göre, Türkiye'de SITC 6, SITC 8 sektöründe rekabet gücünün yüksek olduğu 
görülmüştür. SITC 5 endüstri grubunda ise Türkiye'nin rekabet gücüne sahip olmadığı sonucuna ulaşılmıştır. Brezilya'da ve Rusya'da SITC 5, SITC 7 ve SITC 8 endüstri gruplarında rekabet dezavantajının olduğu görülmüştür. Çin'de SITC 6, SITC 7 ve SITC 8 endüstri grubunda endeks değerinin 1'den büyük dolayısıyla bu endüstrilerde rekabet gücünün yüksek olduğu görülmüştür. Hindistan'ın SITC 5, SITC 6 ve SITC 8 endüstri gruplarında rekabet gücüne sahip olduğu sonucuna ulaşılmıştır. Burada BRIC ülkeleri arasında imalat sanayi endüstrisinde Çin'in daha rekabetçi olduğu görülmektedir. Esasında Türkiye'nin imalat sanayisini daha rekabetçi hale getirebilmesi için ve bu rekabeti sürekli kılabilmesi için emek stokunun verimliliğini artırarak üretim ve ihracat profilini Ar-Ge bazlı ürünlere yönelik olarak değiştirmesi gerekmektedir. Diğer bir ifadeyle, sanayide yapısal dönüşümlerin gerçekleştirilmesi gerekmektedir.
KIP endeksi kullanılarak ülke bazlı rekabet güçleri incelendiğinde, Türkiye'nin Brezilya karşısında SITC 6, SITC 7 ve SITC 8 endüstri grubunda katsayı değerlerinin yüksek olduğu görülmüştür. Türkiye'nin Rusya karşısındaki. Ayrıca SITC 5, SITC 6 ve SITC 7 ve SITC 8 endüstri gruplarının tamamında Türkiye'nin Rusya'ya göre rekabet üstünlüğü olduğu sonucuna ulaşılmıştır. Türkiye'nin SITC 6 , SITC 7 ve SITC 8 endüstri grubunda Hindistan'a göre yüksek bir ihracat performansına sahip olduğu görülmüştür. Buna karşın SITC 5 endüstri grubunda Hindistan'ın Türkiye'ye göre ihracat performansının daha yüksek olduğu gözlenmiştir. Türkiye'nin Çin karşısındaki SITC 6 endüstri grubunda katsayının 1'den büyük olduğu görülmüştür. Buna karşılık SITC 7 ve SITC 8 endüstri grubunda Çin'in Türkiye karşısındaki ihracat performansının daha yüksek olduğu görülmüştür.

\section{KAYNAKLAR}

Aktan, C.C. ve Vural, Y.İ. (2004) "Rekabet Gücü ve Rekabet Stratejileri" Ankara, TiSK Yayını Rekabet Dizisi: 2.

Altay, B. ve Gürpınar, K. (2008) "Açıklanmış Karşılaştırmalı Üstünlükler ve Bazı Rekabet Gücü Endeksleri: Türk Mobilya Sektörü Üzerine Bir Uygulama" Afyon Kocatepe Üniversitesi ilBF Dergisi, 10(1): 257-274.

Altıntaş, N. ve Akpolat, A. (2013) "Tekstil Sektöründe Avrupa Birliği ile Türkiye Arasındaki Rekabet Analizi" Kafkas Üniversitesi Iktisadi ve Idari Bilimler Fakültesi Dergisi, 4(6): 33-42.

Amighini, A. (2005) "China in the International Fragmentation of Production: Evidence from the ICT Industry" The European Journal of Comparative Economics, 2(2): 203-219.

Çivi, E. (2001) "Rekabet Gücü : Literatür Taraması" Yönetim ve Ekonomi Dergisi, 8(2): 21-38.

Dulupçu, M.A. (2001) "Küresel Rekabet Gücü Türkiye Üzerine Bir Değerlendirme" Ankara, Nobel Yayın Dağıtım.

Erkekoğlu, H. (2008) "İmalat Sanayi Rekabet Gücü Araştırması: Kayseri Örneği" Ankara, Palme Yayıncılık.

Erkan, B. (2011) “Türkiye'nin Tekstil ve Hazır Giyim Sektörü İhracatında Uluslararası

Rekabet Gücünün Belirlenmesi", Anadolu Üniversitesi Sosyal Bilimler Dergisi, 13(1): 93-110.
Eroğlu, Ö. ve Özdamar, G. (2006) “Türkİmalat Sanayinin Rekabet Gücü ve Beyaz Eşya Sektörü Üzerine Bir Inceleme" Akdeniz Üniversitesi IBBF Dergisi, 11: 85-104.

Koç, M. ve Özbozkurt, O. (2014) "Ulusların rekabet Üstünlüğü ve Elmas Modeli Üzerine Bir Değerlendirme" İşletme ve İktisat Çalışmaları Dergisi, 2(3): 85-91.

Kösekahyaoğlu, L. Ve Özdamar, G. (2011) "Türkiye, Çin ve Hindistan'ın Sektörel Rekabet Gücü Üzerine Karşılaştırmalı Bir İnceleme" Uludağ Üniversitesi Iktisadi ve Idari Bilimler Fakültesi Dergisi, 30(2): 29-49.

Markusen, J. (1992) "Productivity, Competitiveness, Trade Performance and Real Income: The Nexus Among Four Concepts" Minister of Supply and Services, Canada.

Saraçoğlu, B. ve Köse, N. (2000)“Bazı Gıda Sanayilerinin Uluslararası Rekabet Gücü : Makarna, Bisküvi ve Un Sanayi", Proje Raporu: 1-79.

http://www.tepge.gov.tr/dosyalar/yayinlar/31e63e3 216c044cf8dfea05066f53792.pdf

Şahin, D. (2015)“Türkiye ve Çin'in Tekstil ve Hazır Giyim Sektöründe Rekabet Gücünün Analizi" Akademik Bakış Dergisi, 47: 155-171.

Şahinli, M.A. (2012) "Rekabet Gücü:Türkiye ve Avrupa Birliği Üyesi Ülkelerde Canlı Hayvancılık Sektörünün Durumu" YYÜ TAR BIL Dergisi, 22(2): 91-98.

Vergil, H. ve Yıldırım, E. (2006) "AB-Türkiye Gümrük Birliği'nin Türkiye'nin Rekabet Gücü Üzerindeki 
Etkiler" Erciyes Üniversitesi İktisadi ve Idari Bilimler Fakültesi Dergisi, 26:1-21.

Yılmaz, B. (2003) "Turkey's Competitiveness in the European Union: A Comparision with Five Candidate Countries Bulgaria, The Czech Republic,Hungary,Poland,Romanıa and The EU 15"
Ezoneplus Working Paper, 12: 1-20. http://www. ezoneplus.org/archiv/ezoneplus_wp_twelve.pdf.

UN Comtrade Database http://comtrade.un.org/ data/. 